\title{
¿Es la pedagogía el camino a la construcción de aprendizajes significativos?
}

\section{Is pedagogy the road to the construction of significant learning?}

\author{
José Aníbal Bajaña Góngora ${ }^{1}$ \\ jose.bajanag@ug.edu.ec \\ Daira Jamileth Castillo Cobeña ${ }^{2}$ \\ daira.castilloc@ug.edu.ec \\ Vannia Lilibeth Ronquillo Salazar ${ }^{3}$ \\ vannia.ronquillos@ug.edu.ec
}

Recibido: 1/04/2019; Aceptado: 1/06/2019

\section{RESUMEN}

La educación es el proceso formativo en que un individuo se vuelve un estudiante para desarrollar sus capacidades. Este proceso puede realizarse dentro y fuera del aula. La pedagogía, como ciencia, tiene como objeto de estudio la educación, brindándole a esta un conjunto de bases para el proceso de enseñanza aprendizaje. No determina los límites y el docente lo puede demostrar de distintas maneras por qué la educación es todo proceso de influencia. Se realizó una evaluación a la Guía de Observación Aplicada al Desempeño del Contexto Educativo Actual a alumnos de la U.E. Almirante Illingworth, encontrándose que tanto docentes como alumnos cumplen con la misma.

Palabras Clave: pedagogía, estudiante, ciencia, objeto de estudio

\section{ABSTRACT}

Education is a formative process in which an individual becomes a student to develop their abilities. This process can be carried out inside and outside the classroom. Pedagogy, as a science, has as an object of study the education, providing this a set of bases for the teaching learning process, does not determine the limits and the teacher can demonstrate in different ways why education is all influence process.

Keywords: pedagogy, student, science, object of study

\footnotetext{
1 Universidad de Guayaquil, Guayaquil, Ecuador.

2 Universidad de Guayaquil, Guayaquil, Ecuador.

3 Universidad de Guayaquil, Guayaquil, Ecuador.
} 


\section{Introducción}

La pedagogía reflexiona sobre la educación, un área fundamental de la vida de un ser humano y de una sociedad porque el conocimiento abre puertas no sólo en el ámbito profesional sino también, en la vida personal. Es una herramienta de ayuda a través de la cual un profesional puede ayudar a un estudiante a aprender mediante técnicas de estudio más eficaces. Es especialmente útil y básica en la educación porque cada estudiante es un ser unitario con distintos factores externos e internos, es decir, tiene cualidades concretas y talentos que los docentes deben ayudar a desarrollarlas de la mejor manera. A través de herramientas pedagógicas es posible alimentar la autoestima del estudiante, gracias a una educación personalizada que atiende sus necesidades concretas (Cuesa, 2014).

Existen docentes que tienen muchos títulos académicos y bastantes conocimientos; sin embargo, no tienen la capacidad de comunicar y entender a sus estudiantes. Esto sucede porque no llegan a conocerlos. La pedagogía no determina los límites y el docente lo puede demostrar de distintas maneras porque la educación es todo proceso de influencia, de configuración o de desarrollo del hombre. Traducida del griego, significa arte de instruir o educar al niño. En la antigua Grecia se llamaba pedagogos a aquellos esclavos que llevaban los niños, hijos de esclavistas a la escuela. Más tarde el significado de este término se les dio a aquellas personas que tenían una preparación especial para esto, es decir, para educar a los niños. La ya mencionada ha sido considerada como un arte, como una técnica y como una ciencia.

En cada una de las sociedades, desde la esclavitud hasta la actualidad, siempre ha sido necesario darles determinada preparación a las personas. Esta ciencia concentra su atención en el estudio de la actividad del educador y del educando en correspondencia con la concepción característica del proceso pedagógico. Sobre esta base se elabora la teoría y la metodología de su dirección y organización y se perfeccionan el contenido, los métodos, los procedimientos y los medios.

En la etapa actual su desarrollo es sumamente decisivo Su importancia se incrementa en la medida en que los complejos problemas de personalidad del hombre se han convertido en problemas vitales para el movimiento progresivo de la sociedad necesitando la educación.

\section{Desarrollo}

A lo largo de este trabajo se describirá las direcciones del proceso educativo para alcanzar el objeto de estudio de la pedagogía. Todo aquello que acrecienta el ser biológico y espiritual del hombre, mediante una influencia externa es considerado Educación. La educación es un proceso de direccionamiento o de la conducción de medidas que ya existen en el ser, que se propone la configuración física y espiritual del ser.

Como se puede apreciar la pedagogía presenta a la educación como un proceso por esto ha sido considerada como un arte, como una técnica y como una ciencia, como una acción que se cumple por una influencia, por un desarrollo o por ambas cosas a la vez, la educación es su efecto o resultado. 


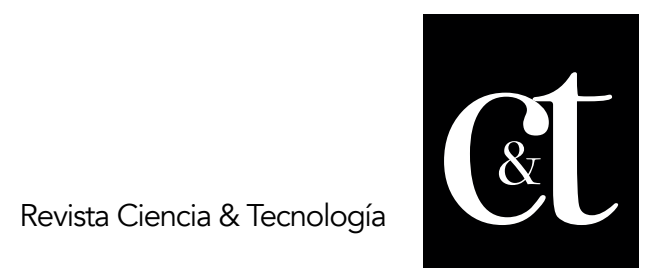

No. 23, 31 de julio de 2019

ISSN impreso: 1390 - 6321

ISSN online: 2661 - 6734

En los inicios del capitalismo como consecuencia de la lucha de la clase burgués floreciente contra el feudalismo, es cuando surge como ciencia independiente, pues interesaba que los trabajadores tuviesen una mejor preparación para operar con las máquinas en las fábricas. En ello tiene gran significación la obra del pedagogo Juan Amos Comenius.

El sistema escolar de la época se encontraba en un estado deplorable. Por ejemplo, solo a los varones se les consideraba dignos de recibir educación, aunque se excluía a los que nacían en la pobreza. La instrucción en las aulas consistía principalmente en llenar la cabeza de los estudiantes con un conocimiento dirigido a manejar las grandes maquinas, palabras y frases del latín. ¿Por qué razón? Porque la Iglesia Católica controlaba la mayoría de las escuelas del medievo, y dado que la liturgia se celebraba en latín, era fundamental la enseñanza de esta lengua para asegurar una provisión constante de futuros sacerdotes.

Además, no se daba atención alguna a fijar objetivos concretos en el aprendizaje, ni tampoco la educación que recibían los alumnos les ayudaba a pasar progresivamente de lo sencillo a lo complicado. La disciplina era severa, en ocasiones incluso cruel, y el ambiente moral, degradado. Comenius no fue el primero que defendió la necesidad de una reforma educativa (Viveros, s.f.).

Pero para Amos Comenius educar era más que llenar la cabeza de alguien con instrucciones y palabras, él quería establecer un sistema de enseñanza avanzado del que todo el mundo pudiera beneficiarse. Decía que a los niños se les debía enseñar por niveles, enlazando de manera natural los conceptos elementales con los conceptos más complejos (Viveros, s.f.).

Además, defendió el uso de la lengua materna durante los primeros años de educación en lugar del latín. Aunque, la educación no debía confinarse a la adolescencia, sino abarcar toda la vida del individuo. Comenius escribió que el estudio tenía que ser "completamente práctico, completamente grato, de tal manera que hiciera de la escuela una auténtica diversión, es decir, un agradable preludio de nuestra vida". También opinaba que la escuela debía centrarse no solo en la formación de la mente, sino de la persona como un todo, lo que incluiría la instrucción moral y espiritual (Viveros, s.f.).

A partir de este momento, la Pedagogía se desarrolló cada vez más y aunque existieron y existen muchas teorías que han trabajado en ello, vale la pena recordar a destacados filósofos y pedagogos por los aportes realizados.

Algunos autores como Lemus (1969), Petrus (1997) y Hernández (2003), la definen como ciencia, arte, saber y disciplina, puede decirse que es un conjunto de normas, leyes y principios que regulan los aprendizajes en el Proceso Educativo. Esta consideración ha dependido de las posiciones ideo-políticas, así como de las concepciones acerca del fenómeno educativo. Se conceptualiza para explicar, sistematizar y transformar la realidad educativa en función de la formación del estudiante a partir de formas escolarizadas y no escolarizadas, además de poseer su propio objeto de estudio, su sistema categorial, sus principios y regularidades, métodos de investigación de ese 


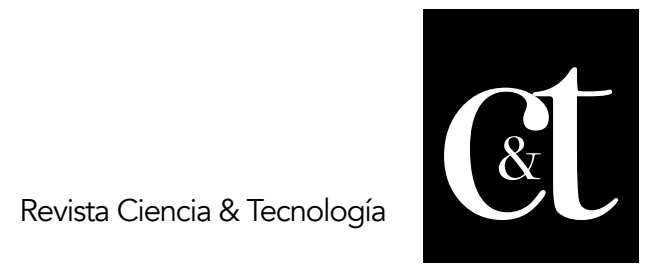

No. 23, 31 de julio de 2019

ISSN impreso: 1390 - 6321

ISSN online: 2661 - 6734

objeto y una concepción filosófica que le sirve de fundamento teórico - metodológico. La Pedagogía estudia las leyes de la dirección del proceso educativo, determina los fundamentos teóricos del contenido y de los métodos de la educación, de la instrucción y de la enseñanza. Estudia y aplica la experiencia más avanzada en la esfera de la educación; refleja la técnica de las ciencias pedagógicas y proporciona al pedagogo el dominio de los métodos y procedimientos más modernos en el campo de la educación y la enseñanza y el complejo arte de la influencia pedagógica sobre el educando, como disciplina es capaz de establecer diversos métodos que posibilitan el análisis dialéctico educativo- cultural. Su etimología está relacionada con el arte o ciencia de enseñar, es decir, mantiene relación entre lo instructivo y lo educativo. Pero más allá de eso se puede hablar mucho de teoría, citar a los autores. Se debe conocer el campo en el conviven docentes y estudiantes, con herramientas como guías de observación entre otras que ayudaran a tener una idea de cómo será la realidad a la que enfrentaran los futuros docentes.

El pedagogo debe poseer una visión amplia y pluralista; primero, porque debe observar los fenómenos educacionales desde diversas perspectivas, Ilámense sociales, políticas, religiosas o psicológicas. Se apela a que sea plural porque no debe hacer distinciones raciales; debe resolver los conflictos con versatilidad y ser abierto en los procesos de enseñanza, En el proceso de enseñanza y aprendizaje del estudiante. La misma convierte al docente en una pieza importante del desarrollo cognitivo, dentro del aula clase, con la finalidad de las correctivas acciones que favorezcan la potencialidad del estudiante.

Hoy en día el uso de las tecnologías de la información y la comunicación es un tema que el pedagogo debe adaptarse a los formatos de éstas a fin de hacer de la educación un proceso interactivo, cuya enseñanza no esté ceñida a un aula de clases, sino que tenga accesibilidad independientemente del lugar donde las personas se ubiquen. Los estudiantes de la carrera Pedagogía de las ciencias Experimentales de la Química y Biología de la facultad de Filosofía de la Universidad de Guayaquil realizaron guías de observación que se aplicaron en la Academia Naval Almirante Illingworth, para analizar el objeto de estudio de la misma. La misma que arrojó como resultados que en dicha institución se emplea de manera adecuada esta ciencia, teniendo un programa de estudios en el que el estudiante es el protagonista y puede construir sus propios conocimientos, teniendo como base la clase impartida. Según el análisis, esto se da debido a que el docente utiliza una metodología correcta para llegar al estudiante, además de incentivarlos a que ellos den su propio criterio y así lograr la construcción de aprendizajes significativos.

\section{Conclusiones}

La Guía de Observación Aplicada al Desempeño del Contexto Educativo Actual, bajo las premisas del Objeto de Estudio de la Pedagogía ayudó a visualizar la construcción de conocimientos de parte de los docentes a estudiantes, la elaboración metodológica para el interaprendizaje, la incentivación al autoconocimiento, el desarrollo de trabajos colaborativos, la impulsión y la guía a la construcción del aprendizaje significativo.

Los resultados obtenidos determinan que se cumple con los objetos de estudios y a lo reglamentado por el Ministerio de Educación por medio de la LOEI que cita que los 


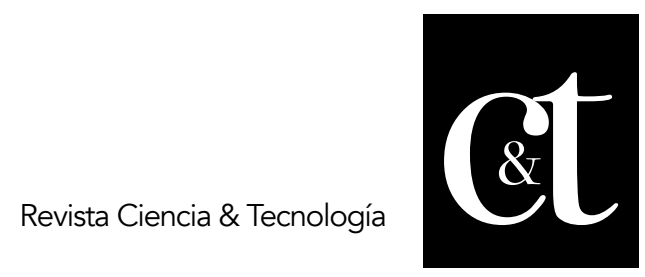

No. 23, 31 de julio de 2019

ISSN impreso: 1390 - 6321

ISSN online: 2661 - 6734

docentes tiene la obligación de atender y evaluar a las y los estudiantes de acuerdo con su diversidad cultural y lingüística y las diferencias individuales además de comunicarles oportunamente, presentando argumentos pedagógicos sobre el resultado de las evaluaciones, también dar apoyo y seguimiento pedagógico, para superar el rezago y dificultades en los aprendizajes y en el desarrollo de competencias, capacidades, habilidades y destrezas (Viveros, s.f.).

Dentro de la Guía de Observación aplicada, se analizó que el estudiante responde de manera acertada a los talleres colectivos o escritos, basándose en sus criterios de aprendizaje, por su parte el docente elabora metodológicamente procedimientos, así como dominio de la temática, una evaluación individualizada reflejada en trabajos colaborativos, así como la incentivación por la participación en clase, cumple con su papel de mediador y guía cognitivo y aplica variantes para el desarrollo de la actividad autónoma promoviendo al criterio de desarrollo personal (Salazar, 2005).

\section{Referencias bibliográficas}

Cuesa, M. (01 de Mayo de 2014). Importancia.org. Recuperado del 12 de Agosto de 2019, de https://www.importancia.org/pedagogia.php

García, I. L. (2005). Uso y aplicaciones de la Pedagogía. Usmp. Recuperado https://www.usmp.edu.pe/publicaciones/boletin/fia/info54/pedagogia.html

Hernández, M. (2008). Pedagogía de la Insumisión. Freire, P. Ed. Contribuciones para la Pedagogía (pp. 223-232). Buenos Aires, Argentina. CLACSO.

Lemus, L. (1997). Pedagogía: Problemas fundamentales. Educación y epistemología. CIDE, Universidad Nacional. Pp. 43-52.

Petrus, A. (1997). Educación social y educación escolar. Pedagogía Social:Revista Interuniversitaria. No. 11 (2004). pp. 87-109.

Salazar, S. F. (2005). El conocimiento pedagógico del contenido como categoría de estudio de la formación docente. Actualidades Investigativas en Educación, 1-18 Recuperado de: https://www.redalyc.org/articulo.oa?id=44750211

Viveros, D. (s.f.). Obtenido de https://www.monografias.com/docs113/algunosaspectos-obra-y-vida-juan-amos-comenio/algunos-aspectos-obra-y-vida- juanamos-comenio.shtml 